\title{
Los crímenes de lesa humanidad en el derecho chileno y en el derecho internacional. Sus requisitos comunes, además de referencias a los actos inhumanos en particular*
}

\author{
Claudia Cárdenas Aravena**
}

\begin{abstract}
RESUMEN
El artículo se ocupa de dilucidar si la tipificación chilena de los crímenes de lesa humanidad es equivalente a la descripción que el derecho internacional realiza de esas conductas punibles. Para eso, parte explicando la relevancia de este examen, continúa abocándose a los requisitos comunes a todos los crimenes de lesa bumanidad y luego pasa revista a los actos inhumanos en particular, deteniéndose especialmente en aquellos que presentan las mayores diferencias con la descripción de las conductas punibles en el derecho internacional. En definitiva, se determina si las diferencias de texto que existen en la descripción de las conductas en el derecho internacional $y$ el derecho interno significan también diferencias materiales. En caso de existir diferencias, se ponen de manifiesto su existencia y potenciales efectos jurídicos.
\end{abstract}

Crímenes de lesa humanidad - requisitos comunes a los crímenes de lesa humanidad tipificación nacional de crímenes contra el derecho internacional

\section{Crimes against bumanity in the Chilean legal system and international law. Common requirements and particular reference to inbumane acts}

\begin{abstract}
This article considers the question whether the description of crimes against humanity in Chilean law is equivalent to the description of international law. It starts explaining the relevance of this question. It continues by analysing the common requirements for crimes against humanity and inbumane acts, especially those in which major differences are presented. In short, it is established whether differences in the legal text also involve substantive differences and what are their potential legal effects.

crimes against humanity - common requirements for crimes against humanity - legal description of crimes against international law

* Este trabajo cuenta con el patrocinio de FONDECYT regular, proyecto No 1120097.

** Doctora en derecho. Profesora Asociada, Facultad de Derecho de la Universidad de Chile. Correo electrónico: ccardenas@derecho.uchile.cl

Artículo recibido el 13 de marzo de 2014 y aceptado para su publicación por el Comité Editorial el
\end{abstract} 29 de octubre de 2014. 


\section{INTRODUCCIÓN: RELEVANCIA DEL ANÁLISIS}

$\mathrm{E}$ 1 genocidio, los crímenes de lesa humanidad y los crímenes y delitos de guerra son conductas cuya punibilidad arranca del derecho internacional, forman parte de los crímenes fundamentales (core crimes) del derecho penal internacional. Ese derecho puede ser aplicado por tribunales internacionales - entre los que hoy destaca la Corte Penal Internacional- o por tribunales estatales. La forma en que los Estados apliquen este derecho depende de su derecho interno. En la legislación vigente, la tipificación del genocidio, los crímenes de lesa humanidad y los crímenes y delitos de guerra están fuera del Código penal, en la Ley $\mathrm{N}^{0} 20.357^{1}$. Este trabajo se dedicará solamente al estudio de los crímenes de lesa humanidad, a su tipificación chilena, y principalmente a determinar si ella es equivalente -más allá de las diferencias de textoa la descripción que el derecho internacional realiza de esas conductas punibles.

Este estudio se considera relevante por varios motivos: en primer lugar, podrá examinarse así en detalle respecto de esta categoría de delitos si, al menos desde el punto de vista de la descripción de conductas punibles y más allá de las diferencias de texto, el legislador ha cumplido con lo que expresamente se esgrimió como razón para dictar la Ley $N^{\circ}$ 20.357: lograr que el juez chileno, aplicando la ley chilena, pueda conocer de las mismas conductas de las que puede conocer la Corte Penal Internacional ${ }^{2}$. En segundo término, una vez que se determine si hay diferencias de fondo o no podrán examinarse las eventuales consecuencias jurídicas de esas eventuales diferencias o falta de ellas. Ámbitos relevantes para esas consecuencias jurídicas podrán ser el ejercicio de la competencia por parte de la Corte Penal Internacional respecto de eventuales crímenes que ocurran en Chile y el eventual ejercicio de jurisdicción extraterritorial de Chile amparándose en el principio de jurisdicción universal. Por último, desde una perspectiva más amplia, el estudio resulta interesante como un caso de implementación nacional en el derecho internacional, que en conjunto con muchos otros podría contribuir a perfilar el desarrollo progresivo del derecho penal internacional.

El trabajo se presentará en tres partes principales: la que sigue a continuación se dedicará a los requisitos comunes a los crímenes de lesa humanidad, abordando su noción y relevancia, amén de su descripción en el derecho chileno y el internacional, poniendo énfasis en las diferencias que se adviertan (II.). Bajo III. se pasará revista a los actos inhumanos en particular, comentándolas con mayor o menor extensión en razón de su mayor discrepancia o equivalencia con las descripciones del derecho internacional. En el punto IV. se examinarán las consecuencias jurídicas de los hallazgos a los que se haya arribado. Cerrará el artículo un apartado de conclusiones.

\footnotetext{
${ }^{1}$ Esto sin perjuicio de que habrá que observar la tramitación del proyecto del nuevo Código Penal pendiente en el Congreso, que incluye la tipificación de crímenes contra el derecho internacional.

${ }^{2}$ Sobre este punto, en general respecto de la Ley N²0.357, cfr. ya Cárdenas Aravena, C., "La implementación de los crímenes internacionales de competencia de la Corte Penal Internacional en la Ley No 20.357", en Revista de Derecho, Universidad Austral de Chile, vol. XXIII, No 2, 2010, pp. 23-44, en particular p. 40 .
} 


\section{LOS REQUISITOS COMUNES A LOS CRÍMENES DE LESA HUMANIDAD}

\section{Alcance de la expresión}

Se ha elegido la expresión "requisitos comunes a los crímenes de lesa humanidad" por sobre la ya usual "elementos del contexto"3, en un sentido similar al que ha utilizado Werle con la expresión "hecho global" 4 , vale decir, incluyendo tanto elementos objetivos (a los que parece aludir el término "contexto") como los subjetivos que deben estar presentes cada vez que se quiera afirmar la existencia de crímenes de lesa humanidad.

\section{Los requisitos comunes a los crímenes de lesa bumanidad en el derecho internacional}

A pesar de tratarse del análisis de una ley penal chilena, se considera pertinente partir pasando somera revista a los requisitos comunes a los crímenes de lesa humanidad en el derecho internacional por razones prácticas: como es sabido, en materia de interpretación de la ley (artículos 19 y siguientes del Código Civil), lo primero que ha de hacer el intérprete es recurrir a su tenor literal, y este, de especial relevancia al describir conductas punibles, ha de entenderse según el sentido corriente de los términos, como regla general. Esta regla general cede, empero, en dos casos: el primero, cuando es la propia ley la que define los términos en algún sentido particular (como sucede por ejemplo en el artículo 2 de la ley que nos convoca); y el segundo, cuando se trata de términos técnicos. La ley chilena $\mathrm{N}^{\circ} 20.357$ contiene terminología técnica abastanza, tomada del lenguaje técnico del derecho penal internacional (de hecho, toma los nomen iuris de los delitos que tipifica directamente del derecho penal internacional) ${ }^{5}$, por lo que vale la pena conocer su significado antes de dedicarnos a ella, para entenderla mejor. Esa parte de la exposición, entonces, procurará centrarse en aspectos que puedan servir de guía para lo que sigue.

En el derecho penal internacional se distinguen los siguientes requisitos comunes a los crímenes de lesa humanidad: en lo objetivo, un ataque y en lo subjetivo el conocimiento de que ese ataque existe y de que se actúa como parte de él.

\footnotetext{
${ }^{3}$ Que se suele usar en resoluciones internacionales y puede ser confundida con esta en cuanto a su alcance, pero es más estricta. Cfr., por todas, Corte Penal Internacional, Sala de Primera Instancia II, Jugement rendu en application de l'article 74 du Statut, caso Fiscalía contra Germain Katanga, de 7 de marzo de 2014, párrafo. 1089 y ss. Consultada en > http://www.icc-cpi.int/iccdocs/doc/doc1744366.pdf<, (visitada en marzo de 2014).

${ }^{4}$ Werle, G. Tratado de derecho penal internacional, 2da. edición, Tirant lo Blanch, Valencia, 2011, pp. 469 y siguientes.

${ }^{5}$ Sobre este tema, in extenso, Cárdenas Aravena, C., "La aplicabilidad del derecho internacional por tribunales chilenos para interpretar la Ley No 20.357”, en Revista de Derecho, Universidad Católica del Norte, vol. XX, No 2, 2013, pp. 212-145.
} 


\subsection{Aspecto objetivo: un ataque}

Los crímenes de lesa humanidad se definen como ciertas conductas que son cometidas en el contexto de un ataque con ciertas características: debe ser generalizado o sistemático y debe dirigirse contra la población civil.

El término ataque se puede describir en proporción a la definición que recoge el artículo 7 párrafo 2 letra a) del Estatuto de Roma de la Corte Penal Internacional (ER): "una línea de conducta que implica la comisión múltiple de actos". Vale decir, un ataque está conformado por una multiplicidad de actos, que tienen entre sí una relación tal que son susceptibles de ser entendidos como una línea de conducta. En doctrina se ha discutido si acaso un ataque puede estar constituido por un solo acto, que genere sin embargo gran cantidad de víctimas. Esta posibilidad ha encontrado algunas voces a favor, pero no ha encontrado acogida en el Estatuto de Roma ${ }^{6}$.

Se ha entendido que un ataque es generalizado cuando alcanza a un gran número de personas, y es sistemático cuando en su ejecución existe un cierto grado de organización que hace observable que en él se sigue un plan o política ${ }^{7}$. Para los efectos de la competencia material de la Corte Penal Internacional, se exige que las conductas constitutivas de crímenes de lesa humanidad se cometan de conformidad con la política de un Estado u organización o para promoverla (artículo 7, párrafo 2 letra a) ER). Es este plan o política lo que une a la multiplicidad de actos de manera que constituyan una "línea de conducta".

Por último este ataque debe tener como objeto a la población civil: habida cuenta de que esta clase de crímenes puede también cometerse fuera del contexto de un conflicto

${ }^{6}$ Cfr. Dixon, R. “Art. 7 Paragraph 2 (a) 'Attack”, en Triffterer. O. (ed.), Commentary on the Rome Statute of the International Criminal Court, 2da. Edición, C.H. Beck, Munich, 2008, p. 234. En doctrina, también asumiendo que debe haber multiplicidad de actos para que pueda hablarse de un ataque en los crímenes de lesa humanidad, Meseke, S. Der Tatbestand der Verbrechen gegen die Menschlichkeit nach dem Römischen Statut des Internationalen Strafgerichtshofes, Berliner Wissenschaftsverlag, Berlín, 2004, pp. 131 y ss.; De Ruiter, D., van der Wolf (eds.), W. Crimes against humanity and international criminal law, International Courts Association, The Hague, 2011, pp. 17 y ss. Negando tajantemente la posibilidad de un ataque que consista en un solo acto, Safferling, Ch. Internationales Strafrecht, Springer, Heidelberg 2011, p. 190. En cuanto a pronunciamientos judiciales, es bastante clara la confirmación de cargos contra Bemba, Corte Penal Internacional, Sala de Cuestiones Preliminares II, Decision Pursuant to Article 61(7)(a) and (b) of the Rome Statute on the Charges of the Prosecutor Against Jean-Pierre Bemba Gombo, de 15 de junio de 2009, párrafo 81.

7 Werle, G. Tratado de derecho penal internacional, 2da. edición, Tirant lo Blanch, Valencia, 2011, pp. 477-479;; Meseke, S. Der Tatbestand der Verbrechen gegen die Menschlichkeit nach dem Römischen Statut des Internationalen Strafgerichtshofes, Berliner Wissenschaftsverlag, Berlín, 2004, p. 133 y ss.; con antecedentes de la jurisprudencia de la Corte Penal Internacional, Beltrán Carpentier, P. "Requisitos comunes a todos los crímenes de lesa humanidad”, en Cárdenas, C. y Fernández, K. (eds.), La Corte Penal Internacional y sus primeros 10 años: un enfoque práctico, Thomson Reuters Chile, Santiago, 2013, pp. 50 y ss.; Sluiter, G. “Chapeau Elements' of Crimes Against Humanity in the Jurisprudence of UN Ad Hoc Tribunals” en Sadat, L. (ed.). Forging a Convention for crimes against bumanity, Cambridge University Press, Cambridge, 2011, pp. 126 y ss.; Ambos, K. "Crimes Against Humanity and the ICC”, en Sadat, L. (ed.). Forging a Convention for crimes against humanity, Cambridge University Press, Cambridge, 2011, pp. 284 y ss.; Schabas, W. The International Criminal Court, A Commentary on the Rome Statute, Oxford University Press, Oxford, 2010, pp. 148 y s. 
armado de los que hacen aplicable el derecho internacional humanitario, mayoritaria y razonablemente se entiende que la noción de población civil para los crímenes de lesa humanidad no es necesariamente idéntica de la que se maneja para los de guerra y que surge del derecho internacional humanitario. Para los efectos de los crímenes en estudio, la noción de población civil abarca a todo grupo de personas unidas por alguna característica común (como vivir en un mismo territorio, o seguir determinadas corrientes políticas o religiosas), excluyendo por cierto al grupo que lleva adelante al ataque ${ }^{8}$.

\subsection{Aspecto subjetivo: conocimiento del ataque y actuar como parte de él}

El artículo 7 párrafo 1 ER explicita el requisito del conocimiento del ataque que ha de tener quien actúa. Además dispone que se ha de actuar "como parte de un ataque...", ergo, entendiendo que esa conducta se inserta en una multiplicidad, conformando una misma línea de conductas con las demás que constituyen el ataque (se actúa en un mismo sentido $)^{9}$.

\section{Los requisitos comunes a los crímenes de lesa bumanidad en el derecho chileno}

La Ley $\mathrm{N}^{\circ} 20.257$ dedica sus dos primeros artículos a los requisitos comunes a todos los crímenes de lesa humanidad. De conformidad con su artículo 1:

"Constituyen crímenes de lesa humanidad los actos señalados en el presente párrafo, cuando en su comisión concurran las siguientes circunstancias:

$1^{\circ}$. Que el acto sea cometido como parte de un ataque generalizado o sistemático contra una población civil.

$2^{\circ}$. Que el ataque a que se refiere el numerando precedente responda a una política del Estado o de sus agentes; de grupos armados organizados que, bajo la dirección de un mando responsable, ejerzan sobre algún territorio un control tal que les

${ }^{8}$ Werle, G. Tratado de derecho penal internacional, 2da. edición, Tirant lo Blanch, Valencia, 2011, p. $47^{\circ}$ y ss.; Meseke, S. Der Tatbestand der Verbrechen gegen die Menschlichkeit nach dem Römischen Statut des Internationalen Strafgerichtshofes, Berliner Wissenschaftsverlag, Berlín, 2004, pp. 148 y ss.; Safferling, Ch. Internationales Strafrecht, Springer, Heidelberg 2011, p. 192; con más antecedentes, Kim, Y. The law of the International Criminal Court, William S Hein \& Co., Buffalo, Nueva York, 2007, p. 50. Hay que dejar constancia sí de que hay resoluciones que emplean el criterio del derecho internacional humanitario en casos en los que los crímenes se cometen en el contexto de un conflicto armado. Cfr., con más antecedentes, la reciente sentencia definitiva del caso Katanga, Corte Penal Internacional, Sala de Primera Instancia II, Jugement rendu en application de l'article 74 du Statut, de 7 de marzo de 2014, párrafo. 1102. Consultada en > http://www. icc-cpi.int/iccdocs/doc/doc1744366.pdf<, (visitada en marzo de 2014).

${ }^{9}$ Cfr., con más antecedentes de doctrina y jurisprudencia que apoyan el criterio, Werle, G. Tratado de derecho penal internacional, 2da. edición, Tirant lo Blanch, Valencia, 2011, p. 484; Meseke, S. Der Tatbestand der Verbrechen gegen die Menschlichkeit nach dem Römischen Statut des Internationalen Strafgerichtshofes, Berliner Wissenschaftsverlag, Berlín, 2004, p. 166 y ss.; Sluiter, G. "'Chapeau Elements' of Crimes Against Humanity in the Jurisprudence of UN Ad Hoc Tribunals” en Sadat, L. (ed.). Forging a Convention for crimes against bumanity, Cambridge University Press, Cambridge, 2011, pp. 133 y ss. 
permita realizar operaciones militares, o de grupos organizados que detenten un poder de hecho tal que favorezca la impunidad de sus actos".

Pueden sistematizarse, a partir de ese artículo, los siguientes requisitos: en lo objetivo, debe existir un ataque con ciertas características, y en lo subjetivo, se debe actuar dolosamente en el contexto de ataque.

\subsection{Aspecto objetivo: un ataque}

Según el artículo 1 de la Ley No 20.357 se requiere que la conducta tenga lugar, en los hechos, dentro de un ataque que reúna determinadas características:

a) debe ser generalizado o sistemático (características definidas en el artículo 2 de la Ley $\mathrm{N}^{\mathrm{0}} 20.357$ ),

b) debe recaer sobre una población civil,

c) debe responder a una política que emane de ciertas fuentes taxativamente enumeradas.

\subsubsection{El ataque debe ser generalizado o sistemático}

Respecto de las características exigidas para el ataque, existe una definición legal que reza como sigue:

“Artículo $2^{\circ}$.- Para efectos de lo dispuesto en el artículo precedente, se entenderá:
$1^{\circ}$. Por 'ataque generalizado', un mismo acto o varios actos simultáneos o inmediata-
mente sucesivos, que afectan o son dirigidos a un número considerable de personas, y
$2^{\circ}$. Por 'ataque sistemático', una serie de actos sucesivos que se extienden por un
cierto período de tiempo y que afectan o son dirigidos a un número considerable
de personas”.

En el derecho chileno se prevé entonces expresamente la posibilidad de que el ataque esté constituido por un solo hecho, siempre que este afecte a un gran número de personas o se dirija contra un gran número de personas. Entonces habrá un ataque generalizado. El ataque también podrá considerarse generalizado si consta de más de un acto, siempre que en ese supuesto los actos sean simultáneos o inmediatamente sucesivos. Con esto, tenemos que lo crucial para distinguir el ataque generalizado respecto del sistemático en el derecho chileno no es la cantidad de personas afectadas por él (como se entiende en el derecho internacional), sino su temporalidad: debe constar de un solo acto o de varios simultáneos o inmediatamente sucesivos.

El ataque sistemático, en tanto, para el derecho chileno también se determina por su extensión temporal: ha de estar conformado por actos sucesivos que se extiendan "por un cierto periodo de tiempo" lo que ha de ser entendido por oposición a la simultaneidad o sucesión inmediata que exige la hipótesis de ataque generalizado. 


\subsection{2. "Contra una población civil"}

Al referirse la ley, entro de un párrafo que denomina "Crímenes de lesa humanidad", a que debe haber un ataque que tenga por objeto a la población civil, parece evidente que utiliza la expresión en su sentido técnico, vale decir, el mismo que se le ha reconocido en el derecho internacional (cfr. supra 2.1). Al no haber una definición legal que apunte en otro sentido ni estar esta interpretación fuera del tenor literal posible de los términos empleados, podemos seguirla. A mayor abundamiento, esta interpretación parece plenamente compatible con el simple requisito de que el ataque afecte o sea dirigido a un "número considerable de personas" que prevé el artículo 2 de la Ley No 20.357.

\subsubsection{El ataque debe responder a una política}

El ataque en cuestión debe responder a una política, que puede emanar taxativamente de:

i) el Estado o de sus agentes;

ii) grupos armados organizados que, bajo la dirección de un mando responsable, ejerzan sobre algún territorio un control tal que les permita realizar operaciones militares, o

iii) grupos organizados que detenten un poder de hecho tal que favorezca la impunidad de sus actos.

La existencia de una política estatales la hipótesis más clásica de crímenes de lesa humanidad. El Estado, que debe proteger a las personas, urde una política que conlleva la comisión de crímenes, lo que provoca en los hechos su casi total indefensión. Ya que el texto no distingue, para la ley chilena ese Estado podría ser el chileno o alguno extranjero.

Un supuesto distinto es el de agentes del Estado que urdan una política. Lo más llamativo es que en este caso no se exige que los agentes del Estado configuren una organización, lo que unido a que el ataque puede estar meramente "dirigido contra" (como hipótesis distinta de afectar) un número considerable de personas parece ampliar bastante los supuestos crímenes de lesa humanidad respecto de lo reconocido en el derecho internacional.

Las otras dos posibilidades de origen de la política están radicadas en grupos organizados. Uno se refiere a grupos armados, con una descripción tomada del Protocolo Adicional II a los Convenios de Ginebra de $1949^{10}$, que en derecho penal internacional es relevante para identificar el contexto de crímenes de guerra, pero el legislador chileno quiso traer a colación a propósito de crímenes de lesa humanidad. El otro se refiere a grupos organizados, pero con una característica relevante: "que detenten un poder de hecho tal que favorezca la impunidad de sus actos”. Como se ha señalado ya en otro

${ }^{10}$ Protocolo Adicional a los Convenios de Ginebra del 12 de agosto de 1949 relativo a la protección de las víctimas de los conflictos armados sin carácter internacional (Protocolo II, de 1977), artículo 1. Consultado en >http:/www.cicr.org/web/spa/sitespa0.nsf/html/protocolo-II < (visitado en marzo de 2014). 
lugar ${ }^{11}$-aunque puede pensarse en ejemplos a los que sea aplicable- esta formulación puede resultar algo críptica. Además, deja fuera supuestos en los que a quienes organicen la comisión de los delitos no puedan ser considerados poderosos ni estén en condiciones de favorecer la impunidad de sus actos, como pudiera darse en alguna organización de actúe simplemente para promover algún cambio social que consideren necesario, estando dispuestos a inmolarse para ello. Es también llamativa la alta exigencia que se realiza respecto de esta clase de organizaciones independientes del Estado, versus la baja exigencia respecto de agentes del Estado que puedan dar origen a una política delictual.

Ya que el listado de la ley es taxativo, la política que emane de cualquier otra fuente no bastará para considerar que existen crímenes de lesa humanidad de acuerdo con el derecho chileno.

\subsection{Aspecto subjetivo: dolo y eventual elemento subjetivo especial}

La descripción del artículo 1 de la Ley $\mathrm{N}^{0} 20.357$ da a entender que el contexto del ataque con determinadas características debe ser abarcado subjetivamente por quien actúa para que pueda imputarse esta clase de delito ${ }^{12}$. Para eso quien actúe debe conocer el contexto de ataque y entender a la conducta que lleva adelante como parte del ataque. Así, el hecho será "cometido como parte del ataque". Ello, por cierto, sin perjuicio del dolo que exija la conducta específica que se lleve a cabo (dolo de matar, de torturar, etc.).

Esta interpretación está en armonía con el artículo 37 de la Ley N 20.357 , que se encuentra ubicado entre las disposiciones comunes a todos los delitos del párrafo a pesar de que su contenido tiene incidencia solo respecto de los crímenes de lesa humanidad. Señala que el grado de conocimiento considerado suficiente se refiere a conocer que la conducta forma parte del ataque exigido (lo que conlleva el conocimiento de que existe), pero no exige que se tenga conocimiento cabal de aspectos concretos del plan o política o del ataque en todo lo que no concierna al acto imputado ${ }^{13}$.

Mención aparte merece, en la tipificación chilena, la posibilidad de que baste que el ataque "se dirija" contra un número considerable de personas como una hipótesis separada de que este ataque "afecte" a un número considerable de personas. Al estar ambas hipótesis unidas por la disyuntiva "o" parece ser que se las entiende como distintas, vale decir, que en el derecho chileno podría haber un crimen de lesa humanidad como delito

${ }^{11}$ Cárdenas Aravena, C., "La implementación de los crímenes internacionales de competencia de la Corte Penal Internacional en la Ley N 20.357", en Revista de Derecho, Universidad Austral de Chile, vol. XXIII, No 2, 2010, p. 28.

${ }^{12}$ Lo que se imputa, claro, no es el contexto en sí, sino el haber actuado dolosamente en ese contexto. Crítico, sobre este punto, van Weezel de la Cruz, A. "Problemas de imputación al tipo penal en crímenes contra la humanidad”, en Gaceta Jurídica, año 2005, No 305, noviembre, pp. 7-14.

13 "Tratándose del numeral $2^{\circ}$ del artículo $1^{\circ}$, es suficiente el conocimiento de que el acto forma parte de un ataque generalizado o sistemático contra una población civil que responde a un plan o política de las características señaladas en el mismo numeral, sin que se requiera el conocimiento de ese plan o política, ni de los aspectos concretos del ataque distintos del acto imputado". 
consumado sin que exista un ataque que afecta a un número considerable de personas, siempre que se haya dirigido contra ellas ${ }^{14}$.

\section{Diferencias entre el orden normativo interno y el internacional}

Por lo desarrollado hasta aquí podemos constatar que, si bien existen amplias coincidencias en los requisitos comunes a los crímenes de lesa humanidad en el derecho internacional y en el derecho interno, existen también algunas diferencias, marcadas por texto expreso en la ley chilena que define términos de manera distinta al derecho internacional o prevé requisitos distintos a los previstos en él.

En definitiva, los puntos más destacables pueden resumirse en los siguientes: alcance del término ataque, exigencia de su sistematicidad o generalidad, el rol de la población civil dentro del delito y lo relativo al denominado "elemento político"15.

\subsection{Alcance del término ataque}

En el derecho chileno es claro que un ataque puede estar constituido por un solo acto, siempre que afecte a un número considerable de personas. Este aspecto es entonces menos exigente que el necesario para que crímenes de lesa humanidad caigan bajo la competencia de la Corte Penal Internacional, pues su Estatuto exige que el ataque consiste en una comisión múltiple de actos. Con ello, Chile marca su posición respecto de un punto no absolutamente zanjado a nivel internacional, que se inclina en la última década más bien por la posición contraria (vid. supra).

\subsection{Exigencia de la sistematicidad o generalidad del ataque}

En este caso, más allá de las definiciones chilenas ya reproducidas, en la práctica se requiere, para nuestro derecho interno, que el ataque siempre sea sistemático en la nomenclatura del derecho internacional, pues se le exige que siempre responda a un plan o a una política. En cuanto al requisito de que afecte a un número considerable de personas - descrito en la definición chilena de ataque sistemático y ataque generalizado- él parece tener su paralelo en la necesaria afectación de la población (término que implica multiplicidad de personas) en el derecho internacional. En la práctica los casos de crímenes de lesa humanidad que han llegado a conocerse por tribunales han

${ }^{14}$ En derecho penal internacional se ha interpretado la exigencia de que el ataque se dirija contra la población civil (que es explícita en la versión en inglés del Estatuto de Roma y el del Tribunal Penal Internacional para la ex-Yugoslavia, pero no como disyuntiva a la afectación), se ha exigido que la población civil sea el blanco principal del ataque. Cfr., con más antecedentes, Sluiter, G. “'Chapeau Elements' of Crimes Against Humanity in the Jurisprudence of UN Ad Hoc Tribunals” en Sadat, L. (ed.). Forging a Convention for crimes against bumanity, Cambridge University Press, Cambridge, 2011, pp. 118 y ss.

15 Werle, G. Tratado de derecho penal internacional, 2da. edición, Tirant lo Blanch, Valencia, 2011, pp. 479 y ss.; Meseke, S. Der Tatbestand der Verbrechen gegen die Menschlichkeit nach dem Römischen Statut des Internationalen Strafgerichtshofes, Berliner Wissenschaftsverlag, Berlín, 2004, pp. 137 y ss. 
implicado ataques sistemáticos, donde es reconocible un plan o política ${ }^{16}$, por lo que las diferencias de texto en este aspecto aparentemente no resultarán relevantes en la práctica.

\subsection{Rol de la población civil dentro del delito}

Como ya se ha destacado, lo que más llama la atención en este punto es la posibilidad de que baste que el ataque esté dirigido contra un número considerable de personas, en oposición a su afectación. Esta diferencia sí podría tener relevancia jurídica, pues para que el delito se consume no sería necesario que se haya afectado a un número considerable de personas, sino que bastaría que se apunte a ello, dirigiéndose el ataque contra ellas. Esto hace que en la legislación chilena actual sea más fácil ${ }^{17}$ castigar ya los primeros actos de un ataque como crímenes de lesa humanidad, pues no sería necesario, para alcanzar la calidad de delito consumado ${ }^{18}$, que una "población" (o número considerable de personas) se haya visto, en los hechos, afectada, lo que suele llevar tiempo. Eso puede suplirse por la conciencia que tenga quien actúa que su conducta se dirige contra un número considerable de personas, y parece acorde con el hecho de que se prevea la posibilidad de que el ataque pueda estar constituido por un solo acto, pues entonces, al momento de actuar, no habrá todavía población afectada.

\subsection{El "elemento político"}

El derecho chileno, siguiendo en esto al Estatuto de Roma, exige como requisito sine qua non lo que se da en denominar el "elemento político". En la práctica de la Corte, este elemento se ha entendido como la exigencia de un cierto grado de organización o plan que una a los diversos actos haciéndolos reconocibles como una línea de conducta ${ }^{19}$. La principal diferencia, incluso con el Estatuto de Roma, es el posible origen de esta política: ambas regulaciones coinciden en que una política

${ }^{16}$ Cfr., a saber, la reciente Corte Penal Internacional, Sala de Primera Instancia II, Jugement rendu en application de l'article 74 du Statut, caso Fiscalía contra Germain Katanga, de 7 de marzo de 2014, párrafo. 1142 y ss. Consultada en >http://www.icc-cpi.int/iccdocs/doc/doc1744366.pdf<, (visitada en marzo de 2014). Con más antecedentes jurisprudenciales de distintos tribunales a lo largo de varias décadas, Mettraux, G. “The Definition of Crimes Against Humanity and the Question of a 'Policy' Element”, en Sadat, L. (ed.). Forging a Convention for crimes against humanity, Cambridge University Press, Cambridge, 2011.

${ }^{17}$ Comparando la situación por ejemplo con los crímenes de competencia de la Corte Penal Internacional, en que es necesario conocer al ataque, que consiste en la comisión múltiple de actos, o sea, ya deben haber ocurrido esos actos, lo que dificulta que las primeras conductas que conforman el ataque puedan ser conocidas por ese tribunal. El mismo criterio se sigue en el proyecto de convención sobre crímenes de lesa humanidad (artículo 3) de la Washington University School of Law, publicado en Sadat, L. (ed.). Forging a Convention for crimes against humanity, Cambridge University Press, Cambridge, 2011, pp. 364 y ss.

${ }^{18}$ Ante la Corte Penal Internacional cabrá examinar la posibilidad de un delito intentado si ha habido actos "que supongan un paso importante para la ejecución” del delito, según el artículo 25 párrafo 3 letra f ER.

${ }^{19}$ Cfr. Beltrán Carpentier, P. "Requisitos comunes a todos los crímenes de lesa humanidad”, en Cárdenas, C. y Fernández, K. (eds.), La Corte Penal Internacional y sus primeros 10 años: un enfoque práctico, Thomson Reuters Chile, Santiago, 2013, pp. 52 y ss. 
estatal es suficiente. La otra posibilidad prevista en el Estatuto de Roma es que la política provenga de una organización. A este respecto, la ley chilena comprende dos hipótesis más estrictas y una, especial, más amplia: es más estricta en cuanto a que la política no puede emanar de cualquier organización, sino solamente de aquellas que cumplan con ciertas características (vid. supra 3.1.3.). Así, si la política emanara de una organización distinta, Chile no podría conocer de la conducta punible como crimen de lesa humanidad $^{20}$. En cambio, la legislación chilena incluye un supuesto en el que no se requiere expresamente que la política emane de una organización, sino que bastaría una simple pluralidad de personas ${ }^{21}$ siempre que estas sean agentes del Estado. En supuestos como este, si esa pluralidad de personas no conformara una organización, la conducta no caería bajo la competencia material de la Corte Penal Internacional.

\section{CONDUCTAS DESCRITAS COMO "ACTOS INHUMANOS" EN LOS CRÍMENES DE LESA HUMANIDAD}

Como es sabido, no basta un contexto de ataque contra la población civil para que cualquier delito que se cometa sea un crimen de lesa humanidad. De hecho, tampoco cualquier conducta delictiva es apta para constituir parte de un ataque, sino las que están expresamente enumeradas, y que se conocen con la denominación genérica de "actos inhumanos". En la ley chilena esta enumeración se realiza entre los artículos tres y nueve de la Ley No 20.359, mientras que en el derecho internacional la enumeración más fácilmente consultable es la del artículo 7 párrafo 1 del Estatuto de Roma.

En general, el listado de conductas coincide ampliamente, incluyendo algunas que no presentan variación respecto de los delitos comunes del Código Penal -caso en el cual no se comentarán mayormente- y otras que ameritan algún comentario adicional. En lo que sigue pasaremos revista a cada una de las conductas tipificadas en la ley nacional como actos inhumanos susceptibles de ser considerados crímenes de lesa humanidad si cumplen con los requisitos comunes tratados antes. Al efecto se abandona el orden seguido por la Ley $\mathrm{N}^{\circ} 20.357$, por considerarlo demasiado intrincado. Se sigue en cambio el orden dispuesto en el artículo 7 del Estatuto de Roma de la Corte Penal Internacional.

${ }^{20}$ Seguramente sí como delito común: homicidio, lesiones, secuestro, violación etcétera.

${ }^{21}$ Acerca de la diferencia entre uno y otro, Werle, G. y Burghardt, B. “¿Requieren los crímenes de lesa humanidad de la participación de un Estado o de una organización 'cuasiestatal'?”, en Cárdenas, C. y Fernández, K. (eds.), La Corte Penal Internacional y sus primeros 10 años: un enfoque práctico, Thomson Reuters Chile, Santiago, 2013, pp. 303-327, en particular p. 305 y ss. Con referencias a resoluciones de la Corte Penal Internacional sobre el punto, Beltrán Carpentier, P. "Requisitos comunes a todos los crímenes de lesa humanidad”, en Cárdenas, C. y Fernández, K. (eds.), La Corte Penal Internacional y sus primeros 10 años: un enfoque práctico, Thomson Reuters Chile, Santiago, 2013, pp. 52 y ss. 


\section{Actos inbumanos en particular}

\subsection{Homicidio}

Lo tipifica el artículo 4 de la Ley $\mathrm{N}^{\circ} 20.357$, en los mismos términos del homicidio del Código penal ("el que mate a otro"). En derecho internacional también puede castigarse como crimen de lesa humanidad de homicidio la causación a otro de lesiones que en el curso normal de los acontecimientos causarán la muerte. Esa conducta sería asimismo punible en el derecho chileno, pero si falta el resultado de muerte no como delito consumado.

\subsection{Exterminio}

En el derecho internacional se lo entiende como dar muerte a un número considerable de personas, o someter intencionalmente a parte de la población a condiciones de vida encaminadas a acarrear su destrucción ${ }^{22}$. La ley chilena trata separadamente ambas hipótesis. La más cercana a la primera la contempla en el artículo 3 de la Ley $\mathrm{N}^{\mathrm{o}} 20.357$, que exige al menos una muerte. Su diferencia mayor con el homicidio estaría proporcionado por el requisito subjetivo de "el propósito de dar muerte a una cantidad considerable de personas”. La segunda hipótesis está tipificada en el artículo $7 \mathrm{~N}^{\circ} 2$ de la Ley No 20.357. Así, la tipificación chilena de la primera hipótesis es menos exigente en lo objetivo, pero más estricta en lo subjetivo, con la dificultad que conlleva probar en todos los casos esa subjetividad particular, y la segunda es equivalente a la del derecho internacional.

\subsection{Esclavitud}

Las conductas ligadas a la esclavitud están tipificadas en el artículo $5 \mathrm{~N}^{\circ} 6$ de la Ley $\mathrm{N}^{\circ}$ 20.357. Es punible, como en el derecho internacional, el ejercer alguno de los atributos del dominio respecto de una persona. Eso sí, la ley chilena exige además una subjetividad especial -que no es relevante desde el punto de vista del derecho penal internacional- para entender que existe esclavitud: se han de satisfacer ciertos propósitos (lucrativos, sexuales, laborales u otros semejantes). Así, la tipificación nacional es más exigente que la del derecho internacional. Cierto es que difícilmente se puede imaginar casos en los que propósitos como los mencionados no concurran al cosificar a una persona, pero en el derecho internacional no resulta necesario probarlos separadamente.

Mención aparte merece la referencia a "la trata o tráfico de esclavos". Hubiera quedado más coherente una mención a la trata o tráfico de personas, que son conductas hoy tipificadas en el Código Penal (artículos 411 bis y 411 ter, que son posteriores a la

${ }^{22}$ Artículo 7 ER, en su párrafo 1 letra b y párrafo 2 letra b. Con más antecedentes, Werle, G. Tratado de derecho penal internacional, 2da. edición, Tirant lo Blanch, Valencia, 2011, pp. 489 y ss. 
ley de marras) ${ }^{23}$. La diferencia en el término empleado (esclavos por personas) hace que a primera vista aparezca una diferencia que resulta incomprensible, máxime si, según la legislación chilena, en el tráfico de migrantes ha de actuarse con ánimo de lucro y en la trata se exige una finalidad de explotación.

\subsection{Deportación o traslado forzoso}

A la descripción de esta conducta se dedica el artículo 9 de la Ley $\mathrm{N}^{0}$ 20.357, actualmente vigente, sin que se aprecien diferencias entre esa descripción y el núcleo de las conductas punibles en el derecho internacional ${ }^{24}$. Eso sí, los requisitos contenidos en el Estatuto de Roma en cuanto a la ausencia de motivos legítimos según el derecho internacional para justificar el desplazamiento y a la necesidad de que las personas hayan estado legítimamente del lugar del que se los fuerza desplazarse, serían útiles en el derecho chileno para fijar como estándar de esa legitimidad al derecho internacional, resguardando así a la población frente a la normativa interna ${ }^{25}$.

\subsection{Privación de libertad ambulatoria}

El artículo $5 \mathrm{~N}^{\circ} 7$ de la Ley $\mathrm{N}^{\circ} 20.357$ pone como requisito que la privación de libertad dure más de cinco días. Resulta discutible que la gravedad de la privación de libertad pueda medirse solo o en primer lugar por su duración. En derecho internacional se requiere más bien que la privación de libertad sea grave, siendo la encarcelación el ejemplo arquetípico ${ }^{26}$.

\subsection{Tortura}

La conducta de tortura se encuentra tipificada en el artículo $7 \mathrm{~N}^{\circ} 1$ de la Ley $\mathrm{N}^{\circ} 20.357$ en términos equivalentes a los del derecho penal internacional para la tortura como crimen de lesa humanidad: se castiga el infligir intencionalmente sufrimientos

${ }^{23}$ En el Estatuto de Roma se pone como ejemplo la trata de personas en sus versiones en inglés y francés. Por lo que aparentemente es un error de traducción, en la versión en español el ejemplo se refiere al tráfico de personas (artículo 7 ER, párrafo 1 letra c y párrafo 2 letra c).

${ }^{24}$ Artículo 7 ER, párrafo 1 letra d y párrafo 2 letra d). Werle, G. Tratado de derecho penal internacional, 2da. edición, Tirant lo Blanch, Valencia, 2011, pp. 498 y ss.; Meseke, S. Der Tatbestand der Verbrechen gegen die Menschlichkeit nach dem Römischen Statut des Internationalen Strafgerichtshofes, Berliner Wissenschaftsverlag, Berlín, 2004, pp. 200 y ss.

${ }^{25}$ Como la que ha conocido Chile en su historia reciente, que vulneró el derecho a vivir en el país del que se es nacional: Cfr. el artículo 22 párrafo 5 de la Convención Americana sobre Derechos Humanos: "Nadie debe ser expulsado del territorio del Estado del cual es nacional ni ser privado del derecho a ingresar en el mismo". El artículo 12.4 del Pacto Internacional de Derechos Civiles y Políticos establece: "Nadie podrá ser arbitrariamente privado del derecho a entrar en su propio país".

26 Werle, G. Tratado de derecho penal internacional, 2da. edición, Tirant lo Blanch, Valencia, 2011, pp. 503 y ss. 
graves a una persona que se tiene bajo custodia. Si bien la mención a que las penas o sanciones lícitas no se considerarán torturas también se hace en el derecho internacional, en el derecho chileno podría haberse explicitado que el parámetro para la licitud de las sanciones es el derecho internacional.

\subsection{Violación}

Para este acto inhumano la Ley $\mathrm{N}^{\circ} 20.357$ (artículo $5 \mathrm{~N}^{\circ} 8$, primera parte y artículo $8 \mathrm{~N}^{\mathrm{o}}$ 3) contiene una remisión a los artículos 361, 362 y $363^{27}$ del Código Penal. Esta descripción, en algunos de sus supuestos, es más exigente que la del derecho penal internacional, en donde basta, para que haya violación, cualquier penetración sexual a otro sin su voluntad ${ }^{28}$.

\subsection{Embarazo forzado}

El artículo $5 \mathrm{~N}^{\circ} 5$ de la Ley $\mathrm{N}^{\circ} 20.357$ y el último inciso del artículo 5 tipifican como conducta punible causar el embarazo de una mujer constriñéndola mediante violencia o amenaza. En el derecho internacional la conducta es distinta y más compleja ${ }^{29}$, pues consiste en "el confinamiento ilícito de una mujer a la que se ha dejado embarazada por la fuerza” unido a ciertas intenciones: la modificación étnica de la población o la comisión de otras violaciones graves del derecho internacional. En el derecho chileno esa conducta también sería punible, concursando las disposiciones referidas al comienzo de este párrafo con las relativas a la privación de libertad. Con todo, no hay una figura penal perfectamente equivalente a lo que en derecho internacional se conoce como embarazo forzado.

\subsection{Esterilización forzada y otras formas de violencia sexual}

Se abordarán otras conductas agrupadas en el artículo 7 párrafo 1 letra g ER. La esterilización forzada se encuentra tipificada en el artículo $5 \mathrm{~N}^{0} 1-3$ de la Ley $\mathrm{N}^{0} 20.357$, sin variaciones respecto de lo que se exige para la punibilidad de la conducta en el derecho internacional ${ }^{30}$. Por su parte, la esclavitud sexual no está especialmente prevista, pero es igualmente punible en el derecho chileno como una forma especial de esclavitud. La prostitución forzada está tipificada en el artículo $5 \mathrm{~N}^{\circ} 9$ y luego mencionada en el

${ }^{27}$ El estupro chileno, que se incluye bajo este título por caer más bien bajo concepto internacional de violación.

${ }^{28}$ Cfr. los Elementos de los Crímenes para el artículo 7 párrafo 1 letra g > http://www.icc-cpi.int/ NR/rdonlyres/A851490E-6514-4E91-BD45-AD9A216CF47E/283786/ElementsOfCrimesSPAWeb.pdf< (consultado en marzo de 2014). Más antecedentes en De Brouwer, A. Supranational criminal prosecution of sexual violence, Intersentia, Antwerpen-Oxford, pp. 103 y ss.

29 Artículo 7, párrafo 1 legra g y párrafo 2 letra f ER.

${ }^{30}$ Werle, G. Tratado de derecho penal internacional, 2da. edición, Tirant lo Blanch, Valencia, 2011, pp. 516 y s. 
párrafo segundo del artículo 5 de la Ley N 20.357 en el contexto de una regulación de pena. La ley chilena tipifica también otras formas de violencia sexual como actos inhumanos, en concreto los abusos sexuales de los artículos 365 bis, 366, 366 bis y 366 ter del Código Penal (artículo $5 \mathrm{~N}^{\circ} 8$, segunda parte y artículo $8 \mathrm{~N}^{\circ} 3$ de la Ley $\mathrm{N}^{\circ} 20.357$ ).

\subsection{Persecución}

La persecución no está prevista como una forma de cometer crímenes de lesa humanidad en el derecho chileno ${ }^{31}$. Eso sí, en el artículo 39 de la Ley $\mathrm{N}^{0} 20.357$, segunda parte, se prevé como agravante específica para los crímenes de lesa humanidad el haber actuado por motivos de discriminación, que es uno de los elementos característicos de este delito (privación grave de derechos por motivos discriminatorios) ${ }^{32}$.

\subsection{Desaparición forzada de personas}

El artículo 6 de la Ley $\mathrm{N}^{\circ} 20.357$ tipifica esta conducta en términos equivalentes a los del derecho internacional ${ }^{33}$.

\subsection{Apartheid}

No está tipificado como forma específica de cometer crímenes de lesa humanidad. Se prevé sin embargo que si en la comisión de las conductas tipificadas como formas de cometer crímenes de lesa humanidad concurriera el requisito subjetivo de ese delito -la finalidad de oprimir y dominar sistemáticamente a un grupo racial o mantener ese estado- eso tendrá incidencia en la pena aplicable (artículo 10 de la Ley No 20.357).

1.13. Otros actos inhumanos de carácter similar que causen intencionalmente grandes sufrimientos o atenten gravemente contra la salud mental o física

La ley chilena no contiene una descripción de la conducta equivalente a "otros actos inhumanos de carácter similar que causen intencionalmente grandes sufrimientos o atenten gravemente contra la salud mental o física”, pero sí prevé la punibilidad de

${ }^{31}$ Sí en el derecho penal internacional, cfr. artículo 7, párrafo 2 letra h y párrafo 2 letra g ER, artículo 18 letra e del proyecto de Código de crímenes contra la paz y seguridad de la humanidad de 1996. Consultado en >http://legal.un.org/ilc/texts/instruments/english/commentaries/7_4_1996.pdf< (visitado en marzo de 2014); artículo 5 letra h del Estatuto del Tribunal Penal Internacional para la ex-Yugoslavia. Consultado en > www.icty.org < (visitado en marzo de 2014).

32 Como se ha hecho notar ya, no se entiende por qué esta agravante se considera solamente para esta clase de delitos. Cfr., Cárdenas Aravena, C., "La implementación de los crímenes internacionales de competencia de la Corte Penal Internacional en la Ley N 20.357 ", en Revista de Derecho, Universidad Austral de Chile, vol. XXIII, N², 2010, p. 39.

33 Artículo 7 ER, párrafo 1 letra i y párrafo 2 letra i. Werle, G. Tratado de derecho penal internacional, 2da. edición, Tirant lo Blanch, Valencia, 2011, pp. 528 y ss. 
ciertas conductas que en el derecho internacional caerían bajo esa descripción. Es el caso de las conductas tipificadas en los artículos $5 \mathrm{~N}^{\circ} 4$ (aborto forzado) y $8 \mathrm{~N}^{\circ} 1$ y 2 , y $8 \mathrm{~N}^{\circ} 1$, que se pueden describir genéricamente como lesiones, además del artículo 8 $\mathrm{N}^{\circ} 3$ de la Ley $\mathrm{N}^{\mathrm{0}} 20.357$, referido a someter a otro a experimentos médicos, extracción de órganos o algún tratamiento médico no consentido que pusiere en grave peligro su vida o su salud. Otras conductas que puedan no coincidir con estos casos no serán entonces crímenes de lesa humanidad de conformidad con la ley chilena, sin perjuicio de que lo normal será que se trate de conductas igualmente punibles en el derecho legal ordinario (no se valoraría especialmente su comisión en un contexto de ataque contra una población civil, como parte de él).

\section{2. ¿Existe una equivalencia entre las conductas tipificadas como crimenes de lesa humanidad en el derecho chileno y las que lo son según el derecho internacional?}

La revista precedente lleva a constatar que la pregunta acerca de si existe una equivalencia entre las conductas tipificadas como crímenes de lesa humanidad en el derecho chileno y las que lo son de acuerdo con derecho internacional no puede ser respondida de manera general y palmaria. Será necesario un análisis del caso concreto para una respuesta individual. Puede sí aseverarse que el grueso de las conductas que son punibles en derecho internacional como crímenes de lesa humanidad lo son también en correspondencia con la legislación chilena. Hay, sin embargo, márgenes en los que la ley chilena es a veces más exigente que el derecho internacional en cuanto a los requisitos mínimos para considerar ciertas conductas como crímenes de lesa humanidad (como sucede paradigmáticamente con el supuesto de otros actos inhumanos de carácter similar que causen intencionalmente grandes sufrimientos o atenten gravemente contra la salud mental o física), además de supuestos que derechamente no están tipificados como formas de cometer crímenes de lesa humanidad, como son la persecución y el apartheid.

En otros casos, en cambio, la ley chilena es más laxa que el derecho penal internacional en la descripción de actos inhumanos, como ocurre a saber con la posibilidad de que exista un ataque sin que se haya afectado a la población civil, bastando que el ataque se dirija contra ella (vid. supra II. 3.1.3).

\section{CONSECUENCIAS JURídicas DEL EXAMEN PRACTICADO}

En suma, habrá que estarse a los supuestos de cada caso concreto, como siempre en derecho. La combinación de requisitos generales y específicos hace que las posibilidades sean muchísimas e inabarcables en un formato como este. Pero para los efectos de una sistematización, podrían distinguirse, por una parte, los supuestos en los que el derecho chileno está en plena consonancia con el derecho internacional vigente y aquellos en los que presenta variaciones, y, luego, distinguir - dentro de los que presentan variaciones-aquellos casos en los que las variaciones implican ser más o menos exigentes que el derecho internacional para calificar alguna conducta concreta como crimen de lesa humanidad. 
La primera parte de esta distinción (si hay diferencias o no con el derecho internacional actualmente reconocido), puede relevarse para los efectos de otro estudio, más amplio, cuya compleción excedería el propósito de estas líneas y que dice relación con la detección temprana de posibles líneas de evolución del derecho internacional en la materia. Avanzar al respecto exigiría, a partir de las diferencias establecidas aquí (vid. supra), realizar un análisis comparado para ver si en otras legislaciones nacionales se presentan diferencias en el mismo sentido, de manera que sea identificable una práctica común. Una fuente formal relevante del derecho penal internacional es la costumbre internacional, y para ella su formación es relevante la conducta oficial del Estado, como la que se manifiesta, por ejemplo, al dictar leyes, si va acompañada la correspondiente opinio iuris, o convicción de estar obedeciendo un imperativo jurídico ${ }^{34}$. Ese interesante análisis desviaría el foco de este trabajo ${ }^{35}$. Baste con presentar aquí un insumo para él.

La segunda parte de la distinción - determinar si para el caso concreto la legislación chilena es más o menos exigente que el derecho internacional para considerar a alguna conducta punible como crimen de lesa humanidad- puede ser relevante a lo menos en dos ámbitos:

Si resulta que alguna conducta puede ser considerada crimen de lesa humanidad conforme a la legislación chilena, pero no conforme al derecho internacional (por ejemplo, porque la política o plan necesarios emanaron de dos agentes el Estado, que no alcanzan a conformar una organización, y ellos llevan adelante un solo acto), habrá que observar que si bien el Estado chileno está jurídicamente facultado para considerar punible esa conducta conforme a su derecho interno, su sola denominación en ese mismo derecho interno como crimen de lesa humanidad no haría aplicable automáticamente el estatuto jurídico que corresponde a esa clase de conductas conforme al derecho internacional. Eso será especialmente relevante cuando en los procedimientos no solamente esté involucrado el Estado chileno (por ejemplo, si se quisiera invocar el principio de jurisdicción universal para conocer en Chile de esta clase de delitos cuando hayan ocurrido fuera de nuestras fronteras ${ }^{36}$ ).

En cambio, los supuestos en los que de aplicar la tipificación chilena resulta que hay conductas que son punibles como crímenes de lesa humanidad conforme al derecho penal internacional pero no lo son de conformidad con la ley chilena (en particular podría ser un supuesto de otros actos inhumanos de carácter similar que causen intencionalmente grandes sufrimientos o atenten gravemente contra la salud mental que no sea punible conforme a la ley chilena o el ya mentado supuesto de la falta de afectación de la población civil), podrían ser relevantes con miras al cumplimiento del fin último de la legislación

${ }^{34} \mathrm{Al}$ respecto, por todos, Brownlie. I., Principles of Public International Law, 7 ma. edición, Oxford University Press, Oxford, 2008, pp. 3-30; Werle, G. Tratado de derecho penal internacional, 2da. edición, Tirant lo Blanch, Valencia, 2011, pp. 114-117.

${ }^{35}$ Quien se interese en realizar este estudio comparado puede encontrar las legislaciones internas de una gran cantidad de Estados en materia de crímenes contra el derecho internacional en la base de datos www.legal-tools.org (disponible también desde la página de la Corte Penal Internacional, www.icc-cpi.int).

${ }^{36}$ La procedencia jurídica de esa hipótesis daría material para un estudio independiente, pero al menos una voz en la doctrina nacional se ha manifestado a favor de ella. Vid. Aguilar Cavallo, G. "El principio de jurisdicción universal: una propuesta de aplicación en Chile”, en Estudios Constitucionales, Centro de Estudios Constitucionales, Universidad de Talca, julio 2006, pp. 333-366. 
nacional conforme quedó declarada durante su tramitación ${ }^{37}$. Esto sucede porque podríamos abrir la puerta a una impugnación de admisibilidad ante la Corte Penal Internacional ${ }^{38}$ de casos que involucren delitos cometidos en Chile, según la compresión que se tenga del ya asentado test de la misma conducta y la misma persona (same conduct, same person test), en donde la Corte -salvo las excepciones contempladas en el artículo 17 ER- no está jurídicamente facultada para conocer de aquellos casos que involucren a personas que ya están siendo investigadas o procesadas por las mismas conductas, y a contrario sensu sí lo está cuando no se esté investigando o persiguiendo a la misma persona por las mismas conductas. Con todo, este supuesto es, en lo previsible, más bien uno de laboratorio, porque lo imaginable es que cualquier acto inhumano que pueda ser considerado punible como crimen de lesa humanidad conforme al derecho internacional sea punible como delito común en el derecho interno, aunque no cumplan los estándares para ser considerados como crímenes de lesa humanidad ${ }^{39}$. Por cierto ha habido voces que entienden que para el test de la misma conducta ha de considerarse la conducta constitutiva de crimen de lesa humanidad en su conjunto (acto inhumano más requisitos comunes) ${ }^{40}$, con lo cual procesos por delitos comunes no cumplirían el estándar. Sin embargo, la forma en que se viene aplicando el test no da cuenta de seguir esta última corriente, sino que se conforma con la existencia de investigaciones y juzgamientos genuinos y reales, sin importar el título de la imputación que haga el Estado ${ }^{41}$.

\section{Conclusiones}

Los criterios básicos para determinar cuándo existen crímenes de lesa humanidad están ya asentados en el derecho penal internacional. Para el derecho interno chileno, esta clase de crímenes siguen siendo un novum ${ }^{42}$, pues si bien la ley que los tipifica tiene ya varios años, no ha tenido aplicación práctica.

${ }^{37}$ Historia de la Ley 20.357. Consultada en >http://recursoslegales.bcn.cl/jspui-rl/bitstream/10221.3/3840/2/ HL20357.pdf< (visitado en marzo de 2014), passim.

${ }^{38}$ Cfr. artículos 17 a 19 ER.

39 Cfr. Cárdenas Aravena, C., "La implementación de los crímenes internacionales de competencia de la Corte Penal Internacional en la Ley N N $^{\circ}$. 357 ”, en Revista de Derecho, Universidad Austral de Chile, vol. XXIII, N 2, 2010, p. 40.

${ }^{40}$ Cfr. Yearbook of the International Law Commission 1996, tomo II, art. 12, p. 38, párrafo 10.

41 Como puede consultarse en la más reciente resolución en la materia, con más antecedentes Corte Penal Internacional, Sala de Cuestiones Preliminares I, Decision on the admissibility of the case against Abdullah Al-Senussi, de 11 de octubre de 2013, párrafo 66, en particular la declaración de que the assessment of the subject matter of the domestic proceedings must focus on the alleged conduct and not on its legal characterisation. Indeed, '(t) he question of whether domestic investigations are carried out with a view to prosecuting 'international crimes' is not determinative of an admissibility challenge' and 'a domestic investigation or prosecution for 'ordinary crimes', to the extent that the case covers the same conduct, shall be considered sufficient'. Consultada en >http://www.icc-cpi. int/iccdocs/doc/doc1663102.pdf<, (visitada en marzo de 2014).

42 Por lo menos en cuanto a conductas tipificadas con ese carácter. Distinto es la declaración que se ha hecho especialmente en sentencias de nuestra Corte Suprema de que delitos tipificados en nuestro derecho 
El estudio que se ha realizado de la tipificación de los crímenes de lesa humanidad permite concluir que también en la tipificación chilena se puede distinguir una estructura bipartita de los crímenes de lesa humanidad, pues para su concurrencia son imprescindibles tanto ciertos elementos comunes como también los requisitos específicos de cada acto inhumano en particular. Tanto para los requisitos comunes como para los actos inhumanos en particular se requiere de la concurrencia de aspectos objetivos y de aspectos subjetivos. Estos, grosso modo, coinciden con los requisitos asentados en el derecho penal internacional. La existencia de variaciones está dentro de las facultades del Estado de Chile de darse el derecho penal que considere más adecuado. Sin perjuicio de ello, resulta interesante comparar lo que en nuestro derecho se consideran crímenes de lesa humanidad con los parámetros del derecho internacional, para poder avanzar en determinar el eventual aporte de Chile al desarrollo progresivo del derecho internacional, para prever eventuales conflictos que a primera vista se pudieran presentar en la admisibilidad de casos por delitos cometidos en Chile ante la Corte Penal Internacional, por la distinta literalidad de varias tipificaciones y también para conocer las posibilidades de aplicación extraterritorial de nuestro derecho penal en esta materia.

Puede dejarse establecido que no hay una tendencia clara en cuanto a la dirección de las discrepancias entre nuestro derecho y el derecho internacional, vale decir, no es que todas las diferencias tiendan a hacer al derecho chileno de aplicación más estricta, o, al revés, que de cada diferencia resulte una aplicación más amplia. Será el juego de las circunstancias, teniendo en cuenta tanto a los requisitos generales como a los específicos de cada acto inhumano, los que hagan determinable para cada caso si es que una determinada conducta que puede ser considerada crimen de lesa humanidad en el derecho interno también lo es en el derecho internacional o viceversa. En cualquier caso, vale reiterar que la regla general será que ambas calificaciones sí coincidan. Acaso las deferencias que en concreto podrían ser más relevantes serían la posibilidad de que un solo acto pudiera configurar un ataque y la de que la política pudiera no emanar de una organización, o las derivadas de las condiciones especiales que deben tener las organizaciones de las que emane el plan o política en la legislación chilena.

\section{BiBLIOGRAFÍA}

\section{Doctrina}

Aguilar Cavallo, G. "El principio de jurisdicción universal: una propuesta de aplicación en Chile", en Estudios Constitucionales, Centro de Estudios Constitucionales, Universidad de Talca, julio 2006, pp. 333-366.

Амво, K. "Crimes Against Humanity and the ICC", en Sadat, L. (ed.). Forging a Convention for crimes against humanity, Cambridge University Press, Cambridge, 2011.

interno como "ordinarios” pueden tener además la calidad e crímenes de lesa humanidad, lo que conlleva consecuencias jurídicas particulares. 
Beltrán Carpentier, P. "Requisitos comunes a todos los crímenes de lesa humanidad”, en Cárdenas, C. y Fernández, K. (eds.), La Corte Penal Internacional y sus primeros 10 años: un enfoque práctico, Thomson Reuters Chile, Santiago, 2013, pp. 49-59.

DE Brouwer, A. Supranational criminal prosecution of sexual violence, Intersentia, Antwerpen-Oxford, pp. 103 y ss.

Brownlie. I., Principles of Public International Law, 7 ma. edición, Oxford University Press, Oxford, 2008.

CÁrdenas Aravena, C., "La implementación de los crímenes internacionales de competencia de la Corte Penal Internacional en la Ley N $\mathrm{N}^{\circ}$ 20.357”, en Revista de Derecho, Universidad Austral de Chile, vol. XXIII, No 2, 2010, pp. 23-44.

CÁrdenas Aravena, C., "La aplicabilidad del derecho internacional por tribunales chilenos para interpretar la Ley N N $^{\circ}$ 20.357", en Revista de Derecho, Universidad Católica del Norte, vol. XX, No 2, 2013, pp. 212-145.

Dixon, R. “Art. 7 Paragraph 2 (a) 'Attack”, en Triffterer. O. (ed.), Commentary onthe Rome Statute of the International Criminal Court, 2da. Edición, C.H. Beck, Munich, 2008.

KIM, Y. The law of the International Criminal Court, William S Hein \& Co., Buffalo, Nueva York, 2007.

Mettraux, G. "The Definition of Crimes Against Humanity and the Question of a 'Policy' Element”, en Sadat, L. (ed.). Forging a Convention for crimes against humanity, Cambridge University Press, Cambridge, 2011.

Meseke, S. Der Tatbestand der Verbrechen gegen die Menschlichkeit nach dem Römischen Statut des Internationalen Strafgerichtshofes, Berliner Wissenschaftsverlag, Berlín, 2004.

De Ruiter, D., van der Wolf (eds.), W. Crimes against humanity and international criminal law, International Courts Association, The Hague, 2011.

SADAT, L. (ed.). Forging a Convention for crimes against humanity, Cambridge University Press, Cambridge, 2011.

SAFFERLING, Ch. Internationales Strafrecht, Springer, Heidelberg 2011.

SchabAs, W. The International Criminal Court, A Commentary on the Rome Statute, Oxford University Press, Oxford, 2010.

SLuiter, G. “'Chapeau Elements' of Crimes Against Humanity in the Jurisprudence of UN Ad Hoc Tribunals" en Sadat, L. (ed.). Forging a Convention for crimes against bumanity, Cambridge University Press, Cambridge, 2011.

VAN Weezel de la Cruz, A. "Problemas de imputación al tipo penal en crímenes contra la humanidad", en Gaceta Jurídica, año 2005, No 305, noviembre, pp. 7-14.

Werle, G. Tratado de derecho penal internacional, 2da. edición, Tirant lo Blanch, Valencia, 2011.

Werle, G. y Burghardt, B. “¿Requieren los crímenes de lesa humanidad de la participación de un Estado o de una organización 'cuasiestatal'?”, en Cárdenas, C. y Fernández, K. (eds.), La Corte Penal Internacional y sus primeros 10 años: un enfoque práctico, Thomson Reuters Chile, Santiago, 2013, pp. 303-327.

\section{Resoluciones}

Corte Penal Internacional, Sala de Cuestiones Preliminares II, Decision Pursuant to Article 61(7)(a) and (b) of the Rome Statute on the Charges of the Prosecutor Against Jean-Pierre Bemba Gombo, de 15 de junio de 2009.

Corte Penal Internacional, Sala de Cuestiones Preliminares I, Decision on the admissibility of the case against Abdullah Al-Senussi, de 11 de octubre de 2013. Consultada en >http:// www.icc-cpi.int/iccdocs/doc/doc1663102.pdf<, (visitada en marzo de 2014). 
CoRTe Penal Internacional, Sala de Primera Instancia II, Jugement rendu en application de l'article 74 du Statut, caso Fiscalía contra Germain Katanga, de 7 de marzo de 2014. Consultada en >http://www.icc-cpi.int/iccdocs/doc/doc1744366.pdf<, (visitada en marzo de 2014).

\section{Otros documentos}

Estatuto de Roma de la Corte Penal Internacional. Consultado en >http://www.icc-cpi.int/NR/ rdonlyres/ADD16852-AEE9-4757-ABE7-9CDC7CF02886/283783/Compendium3rd01SPA. $\mathrm{pdf}<$ (visitado en marzo de 2014).

Estatuto del Tribunal Penal Internacional para la ex-Yugoslavia. Consultado en $>$ www.icty. org < (visitado en marzo de 2014).

Elementos de los Crímenes de la Corte Penal Internacional. Consultado en >http://www. icc-cpi.int/NR/rdonlyres/A851490E-6514-4E91-BD45-AD9A216CF47E/283786/ ElementsOfCrimesSPAWeb.pdf $<$ (visitado en marzo de 2014).

Historia de la Ley $\mathrm{N}^{\circ}$ 20.357. Consultada en >http://recursoslegales.bcn.cl/jspui-rl/bitstream/10221.3/3840/2/HL20357.pdf< (visitado en marzo de 2014).

Protocolo Adicional a los Convenios de Ginebra del 12 de agosto de 1949 relativo a la protección de las víctimas de los conflictos armados sin carácter internacional (Protocolo II, de 1977). Consultado en > http://www.cicr.org/web/spa/sitespa0.nsf/html/protocolo-II< (visitado en marzo de 2014).

Proyecto de código de crímenes contra la paz y seguridad de la humanidad de 1996. Consultado en >http://legal.un.org/ilc/texts/instruments/english/commentaries/7_4_1996.pdf $<$ (visitado en marzo de 2014).

YeArbooK of the International Law Commission 1996, tomo II. 
